\title{
Participatory Hazard Management System and Accident Prevention in the Bonny NLNG Construction Project
}

\author{
Mba Okechukwu Agwu ${ }^{1} \&$ Cletus Izunwanne Emeti ${ }^{1}$ \\ ${ }^{1}$ Faculty of Management Sciences, Business Administration, Niger Delta University, Wilberforce Island, \\ Bayelsa State, Nigeria \\ Correspondence: Mba Okechukwu Agwu, Faculty of Management Sciences, Business Administration, Niger \\ Delta University, Wilberforce Island, Bayelsa State, Nigeria. E-mail: mbaagwu38@yahoo.com
}

Received: May 28, 2013

Accepted: July 10, 2013

Online Published: August 10, 2013

doi:10.5539/ijbm.v8n17p50

URL: http://dx.doi.org/10.5539/ijbm.v8n17p50

\begin{abstract}
The paper examined participatory hazard management system and accident prevention in the bonny NLNG construction project. The research question addressed the extent at which reduced accident/incident rate and increased organizational productivity is dependent on the implementation of participatory hazard management system in the bonny NLNG construction project. It is based on the fundamental behavioural cybernetic principle that those directly affected by workplace hazards, should be primarily responsible for managing and controlling them. The core aspect of the study is the use of cross-sectional survey research design in generating the required primary data. The place of study is the bonny NLNG construction project while the duration of study is between March, 2012 and February, 2013. A sample of 396 (35 supervisors, 98 foremen and 263 workmen) respondents determined at $5 \%$ level of significance for sample error, using Yamane's formula, was selected from a population of 40,568 employees using stratified random sampling method for the purpose of questionnaire administration. The results indicated that reduced accident/incident rate and increased organizational productivity is to a large extent dependent on the implementation of participatory hazard management system in the Bonny NLNG construction project as buttressed by the $82 \%$ and $81 \%$ large extent response rate respectively. It therefore recommends among others: regular site safety audits to identify/eliminate sub-causes of accident, regular staff training to improve their hazard identification skills, formation of health and safety committee to identify/eliminate potential hazards at the task level and making hazard identification/reporting everyone's responsibility.
\end{abstract}

Keywords: hazards, participatory hazard management system, accident prevention, construction project, behavioural cybernetic approach

\section{Introduction}

The need to diversify Nigeria's mono-product economic base and harness its vast natural gas resources/reduce gas flaring led to the incorporation of the Nigeria Liquefied Natural Gas (NLNG) company in May 17, 1989 and the subsequent award of a Turnkey Engineering, Procurement, Installation and Construction (EPIC) contract in December 1995, to a consortium of engineering firms comprising Technip, Snamprogetti, M. V. Kellogg and Japan Gas Corporation (TSKJ), for the construction of the plant, the gas transmission system and the residential area (NLNG, 2013). TSKJ being an engineering design consortium engaged the services of construction firms to execute the project.

Globally, the construction industry has a poor safety record. It remains one of the most dangerous industries in which to work. Statistics from the Health and Safety Executive (HSE) show that U.K. construction workers are approximately five times more likely to be killed and two times more likely to be seriously injured compared to the average for all industries (HSE, 2000; Whitelaw, 2001). U.S. construction workers are over three times more likely to be killed than the all-industry average and one in six construction workers can expect to be injured every year (Kartam, 1997). In 1998 the U.K. average annual fatal accident rate per 100,000 employees was 5.6, while the E.U. average was 13.3 (Whitelaw, 2001). Though there is no reliable construction accident/incident data in Nigeria, in 2005, a four-story building under construction in Port Harcourt collapsed and not less than twenty workers died, in barely 24 hours after a similar incident in Lagos (The Punch, July 2005). 
To ensure a safe work environment with zero accident/incident rate for the construction workforce, a participatory hazard management system with emphasis on hazard identification and elimination was incorporated into the project design and construction contract document in accordance with the provisions of the Mineral Oils (Safety) Regulations 1997. The dangerous nature of construction projects necessitated the need for a participatory hazard management system since it is believed that accident occurs when several causal factors (such as human, technical and environmental) exist coincidentally in a specific time and space (Hollnagel, 2004). Systemic models view accident as an emergent phenomenon rising from the complex interactions between system components resulting in degradation of system performance or accident. Accident is therefore, regarded as the outcome of flawed processes involving interactions of people, social and organizational structures, engineering activities, physical and software system components (Leveson, 2004). A system is regarded as a dynamic process that is continually adapting to changes in itself and its environment to achieve its objectives.

Accident prevention is essential for all organizations because it does not only decrease the number of injuries, property damage, legal liability and financial costs; it also enhances an organization's overall reputation and boosts employee morale. It can be anticipated that with the current trend towards greater involvement of employees in self-management and self-control of workplace hazards, construction incidents/accidents will be reduced to the barest minimum (Bryce, 1981). In construction projects, the implementation of participatory hazard management system based on the cybernetic approach consists of the identification of workplace hazards, anticipation of their potential adverse effects and putting in place appropriate control measures to ensure that the hazards are not released.

A hazard is a physical situation, condition or material property that has the potential to cause harm such as sickness, injury or death to people, damage to property and investments, environmental damage, business interruption and loss of reputation (HSE, 1995). It may also be defined as the intrinsic property or potential of a product, process or situation to cause harm, adverse health effects on someone or damage to something. It can come from a chemical (intrinsic properties), working on a ladder (situation), electricity, a compressed gas cylinder (potential energy), a fire source or more simply a slippery floor. Risk is the likelihood or probability that a person will be harmed or experience adverse health effects if exposed to a hazard or that property will be damaged or lost. The relationship between hazard and risk is exposure, whether immediate or long term. Some hazards associated with construction work include: electricity, sharp edges of rebar, working at heights, noise, toxic substances, falling objects, sharp edges of machines, vehicles in motion and radiation.

Thus, hazard identification/control is a predictive, feed forward process which depends on the behavioural and social interactive skills and competency of the entire construction employees/managers in recognizing, evaluating and controlling workplace hazards (Smith, 1975), since there is a growing scientific evidence that unsafe or defective working conditions in addition to unsafe acts are the primary causal factors in many construction accidents (Hansen, 1982, Hagglund, 1976, Sass \& Butler, 1978). This suggests that construction accidents/incidents prevention is directly and inextricably linked to how the work, workstation and equipment designs are human factored to conform to the behavioural, physiological and performance limitations of the construction employees/managers. Hence, adoption and enforcement of physical safety standards and regulations will not ensure hazard elimination unless the job itself is factored to meet human performance limitations (Smith, 1979). Thus, an injury and illness prevention program will result in workers suffering fewer injuries, illnesses and fatalities. In addition, employers will improve their compliance with existing regulations, and will experience many of the financial benefits of a safer and healthier workplace including significant reductions in workers' compensation premiums. It is against this background that it becomes pertinent to examine participatory hazard management system and accident prevention in the bonny NLNG construction project.

\subsection{Statement of the Problem}

Since inception in 1996, the NLNG construction project with an average workforce of 40,568 persons records an average of 1 fatality, 10 medical treatment cases, 15 first aid cases, 20 near-misses and 50 unsafe acts per annum which is quite infinitesimal considering the magnitude of the workforce and the global construction industry accident statistics(NLNG, 2012). The occurrence of accidents in construction sites usually leads to site closure for accident investigation, loss of man/machine hours, loss of output, high labour turnover, loss of corporate reputation, payment of medical expenses of the injured and payment of compensation/insurance claims for the dead/injured. Workplace incidents cause an enormous amount of physical, financial and emotional hardship for individual workers and their families. Combined with insufficient workers' compensation benefits and inadequate medical insurance, workplace injuries and illnesses can not only cause physical pain and suffering but also loss of 
employment and wages, burdensome debt, inability to maintain a previous standard of living, loss of home ownership and even bankruptcy.

Economic development activities are usually hampered in a country with high rate of construction accidents; since productivity/national output will be low, inflation and rate of unemployment will be high while there will be an increase in social vices. Since accidents originate from flawed processes involving interactions between people, social and organizational structures, engineering activities, and physical and software system components (Leveson, 2004), they can be prevented through the identification and elimination of workplace hazards via the behavioural and social interactive skills and competency of the entire construction employees/managers in recognizing, evaluating and controlling workplace hazards that is deeply rooted in a participatory hazard management system especially in the bonny NLNG construction project. When implemented effectively, it can help workers and their families avoid disruptive and sometimes calamitous impacts on their lives. At the same time, it will help employers avoid the substantial cost impacts and business disruptions that accompany occupational injuries, illnesses and deaths. Not only do employers experience dramatic decreases in workplace injuries, but they often experience a transformed workplace culture that can lead to higher productivity and quality, reduced turnover, reduced costs, and greater employee satisfaction.

\subsection{Research Objectives}

The objectives of the research are as follows:

- To determine the extent at which reduced accident/incident rate is dependent on the implementation of participatory hazard management system in the bonny NLNG construction project.

- To determine the extent at which increased organizational productivity is dependent on the implementation of participatory hazard management system in the bonny NLNG construction project.

\subsection{Research Questions}

The identified gap of ineffectiveness in previous approaches to construction site hazard management/accident prevention, which were either management or employee driven, propelled the development of the participatory (employees/managers) approach to construction hazard management/accident prevention, thus prompting the following research questions:

- To what extent is reduced accident/incident rate dependent on the implementation of participatory hazard management system in the bonny NLNG construction project?

- To what extent is increased organizational productivity dependent on the implementation of participatory hazard management system in the bonny NLNG construction project?

\subsection{Research Hypotheses}

In view of the above research questions, the following null hypotheses were formulated:

$1 \mathrm{H}_{\mathrm{O}}$ : Reduced accident/incident rate is not dependent on the implementation of participatory hazard management system in the bonny NLNG construction project.

$2 \mathrm{H}_{\mathrm{O}}$ : Increased organizational productivity is not dependent on the implementation of participatory hazard management system in the bonny NLNG construction project.

\subsection{Literature Review}

Successful management of construction hazards starts with the identification and assessment of the risks involved. The 1989 Framework Directive (89/391/EEC) placed this responsibility on the shoulders of employers, since they know and control the work processes, they are better placed to identify and control workplace hazards. However, hazard identification and control is organizationally imbibed through a genuine commitment of top management, employees' participation and implementation of appropriate policies, procedures, preventive measures and allocation of resources.

In the 1970s and early 1980s, several industrialized countries introduced detailed construction hazard management regulatory initiatives aimed at dramatically reducing workplace injuries and work-related ill health, which remained notable despite the rise in living standards. These initiatives had at least three main principles of government intervention (Frick \& Wren, 2000). Firstly, they put an emphasis on the responsibility of employers for construction hazard management. Secondly, they introduced better standards and comprehensive legislation to improve health and safety at work. Thirdly, they promoted workers' participation in construction hazard management. The traditional construction hazard management strategy of the 1970s and early 1980s, nevertheless, proved to be unsuccessful and inefficient in reducing workplace injuries and work-related ill-health because it was passive and fragmented in its approach (Walters et al., 2002). Such a traditional 
approach, where regulations from government authorities dictate to employers what should be done to reduce workplace injuries and work-related ill-health, was replaced in the late 1980s and the 1990s by a new approach, that championed the identification and control of workplace hazards from a managerial standpoint (Bluff, 2003). This approach represented a shift from prescriptive legislation to a goal setting philosophy based on the premise that employers and employees are best placed to identify and control workplace hazards. This new participatory approach to hazard management encouraged employers and workers to take responsibility for the identification and control of workplace hazards, through a systematic managerial process (Walters et al., 2002).

From the late 1980s, the concept of systematic hazard management gained increased popularity among construction industry stakeholders (Saksvik \& Quinlan, 2003). The development of the new participatory approach to hazard management across industrialized countries can be explained by several interrelated strands (Frick et al., 2000). Firstly, many private consultancies and public authorities encouraged employers to introduce voluntary hazard management system. Secondly, the debate at the international level on standards, guidelines and audits encouraged employers to introduce participatory hazard management system. Thirdly, a growing number of countries introduced mandatory hazard management strategies (Walters \& Jensen, 2000). An example of this is the publication of the 1989 Framework Directive (89/391/EEC), which defines the key principles for a successful management of health and safety at work, including measures obliging employers to undertake risk assessment and to use preventive measures and social dialogue with employees.

The basic objective of the 1989 Framework Directive was to encourage improvements in workplace health and safety. It established the principle that the employer has a duty to ensure the safety and health of workers in every aspect of their work. The employer is obliged to develop an overall health and safety policy by: assessing work activity risks which cannot be avoided, updating these assessments in the light of changing circumstances, and taking the appropriate preventive and protective measures; making a record of the risk assessment and the list of incidents/accidents at work; informing workers and/or their representatives about potential risks and preventive measures taken; consulting workers and/or their representatives on all health and safety matters and ensuring their participation; providing job-specific health and safety training; designating workers to carry out activities related to the prevention of activity risks; implementing measures on first aid, fire-fighting and emergency evacuation of workers.

The worker, on the other hand, has an obligation to follow the employers' health and safety instructions or to report potential dangers. The 1989 Framework Directive also promotes the workers' right to make proposals relating to health and safety, to appeal to the competent authority and to halt work in the event of serious danger, as part of the participative approach laid down by the Directive. Although participative hazard management has gained considerable attention over the past decades, some are still skeptical of its purpose, perceiving it as a management constraint that introduces more bureaucracy and moves hazard management away 'from the shop floor reality'(Karageorgiou, et al., 2000).

\subsection{Conceptual Framework}

Construction hazard management system cannot function properly without the existence of effective social dialogue, whether in the context of joint safety and health committees or other mechanisms such as collective bargaining arrangements. Workers and their representatives should be given the opportunity, through direct involvement and consultation, to fully participate in the management of workplace hazards in the organization. A system is successful only when all the stakeholders are given defined responsibilities in running it. A major principle of hazard management system is the establishment of a line management responsibility; including the meaningful involvement of all employees at all levels in the organization with defined responsibilities.

It has been demonstrated that the implementation of hazard management system can be successful only when all stakeholders participate fully in its implementation through dialogue and cooperation. A hazard management system solely run by managers without input from workers at lower levels in the hierarchy is bound to lose its focus and fail. A number of studies suggest an association between lower lost-time injury rates and the presence of joint safety committees and trade union involvement in hazard management. Other studies indicate that participatory workplace arrangements lead to safe work practices resulting in improved safety performance even in unionized workplaces.

Full workers' participation is strongly promoted in all ILO occupational health and safety standards, particularly in the ILO Convention on Occupational Safety and Health, 2001 (No. 155) and its accompanying Recommendation (No. 164). For joint safety committees and similar arrangements to be effective, it is important that adequate information and training is provided, effective social dialogue and communication mechanisms are established and workers/their representatives are involved in its implementation. 
Although participation in workplace hazard management entails exchange of information between is employers and employees, it also includes out-sourced and external stakeholders (regulators, subcontractors, insurers, shareholders and consumers). In this context, communication channels between different levels of the organization must be effective and go both ways, meaning that workplace hazard related information and concerns conveyed by shop floor workers should be given due consideration and allowed to reach higher management. This is an example of what is meant by the need for the system to focus on people.

\subsection{Theoretical Framework}

This research is based on the fundamental behavioural cybernetic principle that those directly affected by workplace hazards, should be primarily responsible for managing and controlling them (Bryce, 1981). It assumes that hazard control is a predictive, feed forward process that depends on the behavioural and social interactive skills and competence of the organizational system in recognizing, evaluating and controlling hazards (Smith, 1975). There is growing scientific evidence to suggest that unsafe or defective working conditions in addition to unsafe acts represent primary causal factors in many industrial accidents. This evidence supports the concept that industrial safety is directly and inextricably linked to how work, workstation and equipment designs are human factored to conform to the behavioural, physiological and performance limitations of the employee.

Thus, adoption and enforcement of physical safety standards and negligence regulations will not ensure safe work unless the job itself is factored to meet human needs (Smith, 1979).The foregoing concepts; pave the way for the two tenets of cybernetics safety: self-regulation and employee involvement. The essenceis that, individual workers and organizations most directly affected by workplace hazards should be primarily responsible for managing and controlling them. A major industrial resource for achieving such self-regulation is the employees themselves, whose insight and understanding of their own work operations, conditions and performance demands can be employed for effective detection and predictive control of the effects and scope of job hazards (Viaene, 1980).

\subsection{Participatory Hazard Management System Methodology}

A successful participatory construction hazard management system is characterized by: management commitment, employee involvement, identification and control of hazards, compliance with legislation, safe work practices training, support a culture of safety and continuous improvement.

Management Commitment: This involves: commitment to a health and safety policy; commitment of resources (time, money, and personnel); encouragement of employee participation; responding to all reports of unsafe work practices; going beyond regulations in addressing workplace hazards.

Employee Involvement: This entails: incorporating safety and health responsibilities in job descriptions; making safe work practices part of performance evaluation; setting safety goals and holding everyone accountable; disciplining employees who behave in ways that could harm themselves or others; establishing a clear system of reporting hazards, injuries, illnesses and close calls; recognizing employees who contribute inkeeping the workplace safe and healthy.

Identification and Control of Hazards: This entails: reviewing records of accidents, injuries, illnesses, and close calls; reviewing first aid logs, workers' compensation reports, complaints and close calls; reviewing inspection reports; prioritizing identified hazards; correcting identified hazards using: engineering controls, administrative controls and personal protective equipment; evaluating changes made to ensure that they have corrected the identified hazards.

Compliance with Legislation: Employers must identify the safety regulations that apply in their workplaces and comply with them.

Safe Work Practices Training: Employers must train their workers on the hazards they may be exposed to at work and how to protect themselves, keep records of all training and provide: general safety orientation for new employees and employees starting new jobs; specific training on the hazards of their jobs and how to do their jobs safely.

Support a Culture of Safety: This can be achieved by management: establishing an effective two-way communication that responds to the needs and concerns of workers; going beyond regulations in ensuring a safe workplace; encouraging workers to go "beyond the call of duty" in ensuring a safe workplace; supporting a work environment that fosters trust, creativity and general well-being; celebrating success with SHARP or other recognition programs. 
Continuous Improvement: This can be achieved by a review of the system's strengths and weaknesses by: conducting frequent (daily, weekly as needed) inspections of specific equipment and processes; evaluating injury and illness statistics; investigating accidents, injuries, illnesses and close calls as they occur; evaluating effectiveness of training; ensuring hazard correction systems are in place and working.

\section{Method}

The scope of the research is limited to the ten construction companies (Julius Berger NigeriaPlc., Daewoo Engineering and Electrical Construction Company, Fougerolle Nigeria Limited, Cimimontubi Nigeria Limited, DBN Nigeria Limited, Spibat Nigeria Limited, Bouygues Nigeria Limited, Chicago Bridge and Iron Company Limited, Dumez Nigeria Limited and EtcoNigeria Limited) that are involved in the construction of NLNG trains 4, 5 and 6 projects with emphasis on site supervisors, foremen and workmen who are directly involved in construction activities. An exploratory, cross-sectional perception survey was used in generating the primary data required for the study. The population of study consists of 40,568 workers of three categories $(3,560$ supervisors, 10,028 foremen and 26,980 workmen) drawn from the ten construction companies involved in the construction of NLNG trains 4,5 and 6 projects.

A sample of 396 (35 supervisors, 98 foremen and 263 workmen) determined at 5\% level of significance for sample error, using Taro Yamane's (1964) formula, was selected using stratified random sampling method for the purpose of questionnaire administration. The questionnaire was designed to obtain a fair representation of the opinions of the three categories of workers involved in the construction of NLNG trains 4, 5 and 6 projects using a three-point Likert type scale. The questionnaire responses of the sample respondents were presented using tables, analyzed and interpreted using simple percentages while chi-square $\left(\chi^{2}\right)$ was used in testing formulated hypotheses. A total of 396 copies of the questionnaire were administered, out of which 2 were cancelled while 4 were also not returned and 390(98\%) were used for the analysis.

\section{Results and Discussions}

\subsection{Distribution of Sample Respondents}

The distribution of sample respondents among the three categories of workers in the ten construction companies involved in the construction of NLNG trains 4, 5 and 6 projects is as shown in Table 1 below:

Table 1. Distribution of sample respondents among NLNG construction companies

\begin{tabular}{|c|c|c|c|c|c|}
\hline S/No & Name of Company & $\begin{array}{c}\text { Sample } \\
\text { Supervisors }\end{array}$ & $\begin{array}{l}\text { Sample } \\
\text { Foremen }\end{array}$ & $\begin{array}{c}\text { Sample } \\
\text { Workmen }\end{array}$ & $\begin{array}{c}\text { Total Number of Sample } \\
\text { Respondents }\end{array}$ \\
\hline 1. & Julius Berger Nigeria Plc. & 5 & 11 & 26 & 42 \\
\hline 2. & $\begin{array}{l}\text { Daewoo Engineering and Electrical } \\
\text { Construction Company }\end{array}$ & 4 & 11 & 26 & 41 \\
\hline 3. & Fougerolle Nigeria Limited & 4 & 11 & 26 & 41 \\
\hline 4. & Cimimontubi Nigeria Limited & 3 & 9 & 26 & 38 \\
\hline 5. & DBN Nigeria Limited & 3 & 9 & 26 & 38 \\
\hline 6. & Spibat Nigeria Limited & 3 & 9 & 26 & 38 \\
\hline 7. & Bouygues Nigeria Limited & 3 & 9 & 26 & 38 \\
\hline 8. & $\begin{array}{c}\text { Chicago Bridge and Iron Company } \\
\text { Limited }\end{array}$ & 3 & 9 & 26 & 38 \\
\hline 9. & Dumez Nigeria Limited & 3 & 9 & 26 & 38 \\
\hline 10. & Etco Nigeria Limited & 3 & 9 & 26 & 38 \\
\hline & Total Number of Sample Respondents & 34 & 96 & 260 & 390 \\
\hline
\end{tabular}

Source: Field Survey, 2013.

\subsection{Distribution of Responses on Research Questions}

\subsubsection{Question Number 1}

To what extent does your company implement participatory hazard management system in the execution of the bonny NLNG construction project? 
Table 2. Response pattern on the extent of implementation of participatory hazard management system in the execution of the bonny NLNG construction project

\begin{tabular}{lcccc}
\hline & Category of Respondents & \multicolumn{3}{c}{ Responses Provided } \\
\cline { 2 - 5 } & Large extent & Mild extent & Poor extent & Total \\
\hline Supervisors & 24 & 8 & 2 & 34 \\
Foremen & 80 & 10 & 6 & 96 \\
Workmen & 221 & 30 & 9 & 260 \\
Total & 325 & 48 & 17 & 390 \\
\hline
\end{tabular}

Source: Field Survey, 2013.

Table 2 shows that a total of 325 i.e. $83 \%$ of the workers across the three categories, were of the opinion that their company to a large extent implements participatory hazard management system, 48 i.e. $12 \%$ of the workers are of the view that their company to a mild extent implements participatory hazard management system while 17 workers i.e. 5\% expressed a poor extent opinion. We therefore conclude that there is evidence of a large extent implementation of participatory hazard management system in the execution of the bonny NLNG construction project as buttressed by the $83 \%$ large extent response of the sample respondents.

\subsubsection{Question Number 2}

To what extent is reduced accident/incident rate dependent on the implementation of participatory hazard management system in the bonny NLNG construction project?

Table 3. Response pattern on the extent reduced accident/incident rate is dependent on the implementation of participatory hazard management system in the bonny NLNG construction project

\begin{tabular}{lcccc}
\hline \multirow{2}{*}{ Category of Respondents } & \multicolumn{4}{c}{ Responses Provided } \\
\cline { 2 - 5 } & Large extent & Mild extent & Poor extent & Total \\
\hline Supervisors & 21 & 5 & 8 & 34 \\
Foremen & 74 & 15 & 7 & 96 \\
Workmen & 225 & 30 & 5 & 260 \\
Total & 320 & 50 & 20 & 390 \\
\hline
\end{tabular}

Source: Field Survey, 2013.

Table 3 shows that a total of 320 i.e. $82 \%$ of the entire respondents across the three categories of employees were of the opinion that reduced accident/incident rate is to a large extent dependent on the implementation of participatory hazard management system in the bonny NLNG construction project .50 i.e. $13 \%$ of the respondents were of a mild extent opinion while 20 i.e. $5 \%$ of the respondents were of a poor extent opinion. We therefore conclude that there is strong evidence that reduced accident/incident rate is dependent on the implementation of participatory hazard management system in the bonny NLNG construction project as buttressed by the $82 \%$ large extent response of the sample respondents. This conclusion is supported by the empirical studies of Huang et al., 2009, which observed a $28 \%$ reduction in costs associated with work related injuries/illnesses as a result of the implementation of effective workplace safety programs (participatory hazard management system) in 231 U.S. companies with 100 or more employees.

\subsubsection{Question Number 3}

To what extent is increased organizational productivity dependent on the implementation of participatory hazard management system in the bonny NLNG construction project? 
Table 4. Response pattern on the extent increased organizational productivity is dependent on the implementation of participatory hazard management system in the bonny NLNG construction project

\begin{tabular}{lcccc}
\hline \multirow{2}{*}{ Category of Respondents } & \multicolumn{4}{c}{ Responses Provided } \\
\cline { 2 - 5 } & Large extent & Mild extent & Poor extent & Total \\
\hline Supervisors & 19 & 8 & 7 & 34 \\
Foremen & 75 & 17 & 4 & 96 \\
Workmen & 221 & 32 & 7 & 260 \\
Total & 315 & 57 & 18 & 390 \\
\hline
\end{tabular}

Source: Field Survey, 2013.

Table 4 indicates that a total of 315 i.e. $81 \%$ of the entire respondents across the three categories of employees were of the opinion that increased organizational productivity is to a large extent dependent on the implementation of participatory hazard management system in the bonny NLNG construction project. 57 i.e. $15 \%$ of the respondents were of a mild extent opinion while 18 i.e. $4 \%$ of the respondents were of the opinion that increased organizational productivity is to a poor extent dependent on the implementation of participatory hazard management system in the bonny NLNG construction project. We therefore conclude that there is a strong evidence that increased organizational productivity is dependent on the implementation of participatory hazard management system in the bonny NLNG construction as buttressed by the $81 \%$ large extent response of the sample respondents. This conclusion is also supported by the empirical studies of Huang et al., 2009, which observed a $43 \%$ increase in productivity as a result of the implementation of effective workplace safety programs (participatory hazard management system) in 231 U.S. companies with 100 or more employees.

\subsection{Test of the First Hypothesis}

I. $\mathbf{H}_{\mathbf{O}}$ : Reduced accident/incident rate is not dependent on the implementation of participatory hazard management system in the bonny NLNG construction project.

II. $\mathbf{H}_{1}$ : Reduced accident/incident rate is dependent on the implementation of participatory hazard management system in the bonny NLNG construction project.

III. $\alpha=0.05$.

IV. Degree of Freedom $(\mathrm{df})=(\mathrm{r}-1)(\mathrm{c}-1=(3-1)(3-1)=4$.

V. Decision Rule: Reject Ho: if $\chi_{\mathrm{c}}^{2}>\chi_{\mathrm{t}}^{2}$, Accept Ho: if $\chi_{\mathrm{c}}^{2}<\chi_{\mathrm{t}}^{2}$.

VI. Chi- square critical table value $\left(\chi_{\mathrm{t}}^{2}\right)=\chi_{0.05}^{2}=9.49$.

VII. Chi-square critical computed value $\left(\chi_{c}^{2}\right)$ from table $6=\chi_{c}^{2}=13.6599$.

Table 5. Observed and expected frequencies of table 3

\begin{tabular}{lllll}
\hline \multirow{2}{*}{ Category of Respondents } & \multicolumn{4}{c}{ Responses Provided } \\
\cline { 2 - 5 } & Large extent & Mild extent & Poor extent & Total \\
\hline Supervisors & $21(27.90)$ & $5(4.36)$ & $8(1.74)$ & 34 \\
Foremen & $74(78.77)$ & $15(12.31)$ & $7(4.92)$ & 96 \\
Workmen & $225(213.33)$ & $30(33.33)$ & $5(13.33)$ & 260 \\
Total & 320 & 50 & 20 & 390 \\
\hline
\end{tabular}

Source: Field Survey, 2013. 
Table 6. Computation of Chi-square critical computed value $\left(\chi^{2}{ }_{c}\right)$ from table 5

\begin{tabular}{lllll}
\hline Fo & $\mathrm{Fe}$ & $(\mathrm{Fo}-\mathrm{Fe})$ & $(\mathrm{Fo}-\mathrm{Fe}) / \mathrm{Fe}$ & $(\mathrm{Fo}-\mathrm{Fe})^{2} / \mathrm{Fe}$ \\
\hline 21 & 27.90 & -6.90 & 0.2473 & 0.0612 \\
5 & 4.36 & 0.64 & 0.1468 & 0.0215 \\
8 & 1.74 & 6.26 & 3.5977 & 12.9435 \\
74 & 78.77 & -4.77 & -.0606 & 0.0037 \\
15 & 12.31 & 2.69 & 0.2185 & 0.0478 \\
7 & 4.92 & 2.08 & 0.4228 & 0.1787 \\
225 & 213.33 & 11.67 & 0.0547 & 0.0030 \\
30 & 33.33 & -3.33 & 0.0999 & 0.0100 \\
5 & 13.33 & -8.33 & -0.6249 & 0.3905 \\
& & & & $\chi_{\mathrm{c}}^{2}=\mathbf{1 3 . 6 5 9 9}$ \\
\hline
\end{tabular}

Since $\chi_{c}^{2}>\chi_{t}^{2}$ i.e. 13.6599>9.49, we reject the null hypothesis and accept the alternative hypothesis that reduced accident/incident rate is dependent on the implementation of participatory hazard management system in the bonny NLNG construction project as buttressed by the $82 \%$ large extent response of the sample respondents in Table 3.

\subsection{Test of the Second Hypothesis}

I. $\mathrm{H}_{\mathrm{O}}$ : Increased organizational productivity is not dependent on the implementation of participatory hazard management system in the bonny NLNG construction project.

II. $\mathrm{H}_{1}$ : Increased organizational productivity is dependent on the implementation of participatory hazard management system in the bonny NLNG construction project.

III. $\alpha=0.05$.

IV. Degree of Freedom $(\mathrm{df})=(\mathrm{r}-1)(\mathrm{c}-1=(3-1)(3-1)=4$.

V. Decision Rule: Reject Ho: if $\chi_{\mathrm{c}}^{2}>\chi_{\mathrm{t}}^{2}$, Accept Ho: if $\chi_{\mathrm{c}}^{2}<\chi_{\mathrm{t}}^{2}$.

VI. Chi- square critical table value $\chi_{\mathrm{t}}^{2}=\chi_{0.05}^{2}=9.49$.

VII. Chi-square critical computed value $\left(\chi_{\mathrm{c}}^{2}\right)$ from table $8=\chi_{\mathrm{c}}^{2}=12.685$.

Table 7. Observed and expected frequencies of table 4

\begin{tabular}{lllll}
\hline \multirow{2}{*}{ Category of Respondents } & \multicolumn{4}{c}{ Responses Provided } \\
\cline { 2 - 5 } & \multicolumn{1}{c}{$\begin{array}{c}\text { Large } \\
\text { extent }\end{array}$} & $\begin{array}{c}\text { Mild } \\
\text { extent }\end{array}$ & Poor extent & Total \\
\hline Supervisors & $19(27.46)$ & $8(4.97)$ & $7(1.57)$ & 34 \\
Foremen & $75(77.54)$ & $17(14.03)$ & $4(4.43)$ & 96 \\
Workmen & $221(210)$ & $32(38)$ & $7(12)$ & 260 \\
Total & 315 & 57 & 18 & 390 \\
\hline
\end{tabular}

Source: Field Survey, 2013.

Table 8. Computation of Chi-square critical computed value $\left(\chi_{c}^{2}\right)$ from table 7

\begin{tabular}{lllll}
\hline Fo & $\mathrm{Fe}$ & $(\mathrm{Fo}-\mathrm{Fe})$ & $(\mathrm{Fo}-\mathrm{Fe}) / \mathrm{Fe}$ & $(\mathrm{Fo}-\mathrm{Fe})^{2} / \mathrm{Fe}$ \\
\hline 19 & 27.46 & -8.46 & -0.3081 & 0.0949 \\
8 & 4.97 & 3.03 & 0.6097 & 0.3717 \\
7 & 1.57 & 5.43 & 3.4586 & 11.9619 \\
75 & 77.54 & -2.54 & 0.0328 & 0.0011 \\
17 & 14.03 & 2.97 & 0.2117 & 0.0448 \\
4 & 4.43 & -0.43 & -0.0971 & 0.0094 \\
221 & 210 & 11 & 0.0523 & 0.0027 \\
32 & 38 & -6 & 0.1580 & 0.0249 \\
7 & 12 & -5 & 0.4167 & 0.1736 \\
& & & & $\chi_{\mathrm{c}}^{2}=\mathbf{1 2 . 6 8 5}$ \\
\hline
\end{tabular}


Since $\chi_{c}^{2}>\chi_{t}^{2}$ i.e. $12.685>9.49$, we reject the null hypothesis and accept the alternative hypothesis that increased organizational productivity is dependent on the implementation of participatory hazard management system in the bonny NLNG construction project, as buttressed by the $81 \%$ large extent response of the sample respondents in Table 4.

The paper examined participatory hazard management system and accident prevention in the bonny NLNG construction project. The research question addressed the extent at which reduced accident/incident rate and increased organizational productivity is dependent on the implementation of participatory hazard management system in the bonny NLNG construction project. It assumes those directly affected by workplace hazards, should be primarily responsible for managing and controlling them based on fundamental behavioural cybernetic principle. The three major findings of the research are as follows:

Participatory hazard management system is to a large extent implemented in the execution of the bonny NLNG construction project by the construction companies.

Reduced accident/incident rate is dependent on the implementation of participatory hazard management system in the bonny NLNG construction project.

Increased organizational productivity is dependent on the implementation of participatory hazard management system in the bonny NLNG construction project.

Arising from the findings of this paper, it is suggested that the management of the bonny NLNG construction companies should take the following measures to ensure success in its implementation of participatory hazard management system and incident-free project:

1). Assign safety responsibilities and incorporate them into job descriptions for all organizational levels, from employees on the work floor to senior managers.

2). Regularly exchange information with workers on health and safety performance improvements. Measure things such as the quality of the incident investigations carried out, the number of near hits reported or the number of safety improvement suggestions received.

3). Regular staff training to improve their hazard identification skills. Be clear about the priority of health and safety among other important project priorities.

4). Regular site safety audits to identify/eliminate sub-causes of accident.

5). Create a health and safety committee. Keep a close watch to make sure it continues to function well, e.g. that team meetings are well attended, that there is an even spread of responsibilities/functions and that it has the appropriate authority to implement its decisions.

6). Provide employees with ways to participate, contribute suggestions and raise concerns or problems. Encourage them to share their concerns and ideas for improvement and make supervisors and managers accountable for their responses.

7). Develop a system that tracks hazard controls to ensure corrective actions are taken promptly. Check that corrective actions are further monitored to ensure they have controlled the hazard.

8). Constantly monitor that all injuries, harm and near misses in your workplace are reported, investigated and recorded in your incident register. Make sure your employees understand that it is important to report even minor incidents and near misses. Make sure investigations are effective and are taking place and being completed at the right time.

\section{Acknowledgements}

The authors are grateful to the management and staff of the Bonny NLNG construction companies especially those that completed and returned the research questionnaire. We also appreciate the efforts of Stephen Lee (IJBM editorial assistant) in making the publication of this article possible. Our sincere thanks go to the peer-reviewers for their fair evaluation and useful suggestions/corrections. We thank our family members for their moral support and understanding.

\section{References}

Bluff, L. (2003). Systematic Management of Occupational Health and Safety. Working Paper 20. National Research Centre for Occupational Health and Safety Regulation, Regulatory Institutions Network, Research School of Social Sciences, Australian National University.

Bryce, G. K. (1981). Joint Labour-Management Occupational Health Committes. An Example of Worker 
Participation in Worksite Health and Safety Programs. M. H. A. Thesis. Ottawa: University of Ottawa.

Federal Government of Nigeria. (1997). Mineral Oils (Safety) Regulations. Official Gazette. Lagos: Government Press.

Frick, K., \& Wren, J. (2000). Reviewing occupational safety and health management: multiple roots, diverse perspectives and ambiguous outcomes. In Frick, K., Jensen, P. L., Quinlan, M., \& Wilt Hagen, T. (Eds.), Systematic occupational safety and health management: perspectives on an international development. Bingley: Emerald Group Publishing Limited.

Frick, K., Jensen, P. L., Quinlan, M., \& Wilt Hagen, T. (2000). Systematic occupational safety and health management: an introduction to a new strategy for occupational safety, health and well-being. In Frick, K., Jensen, P. L., Quinlan, M., \& Wilt Hagen, T. (Eds.), Systematic occupational safety and health management: perspectives on an international development. Bingley: Emerald Group Publishing Limited.

Hagglund, G. (1976). Causes of injury in industry-The 'Unsafe Act' Theory. Madison, WI: University of Wisconsin School for Workers.

Hansen, E. (1982). Psychological aspects of accident prevention. Occupational Hazards, 44(2), 115-118.

Health and Safety Executive. (1995). Generic Terms and Concepts in the Assessment and Regulation of Industrial Risks. Discussion Document. London: HMSO.

Health and Safety Executive. (2000). Safety statistics bulletin 1999/2000. London: HMSO.

Hollnagel, E. (2004). Barriers and Accident Prevention. Hampshire: Ashgate.

Huang, Y. H., et al. (2009). Financial decision-makers' views on safety: What SH \& E professionals should know. Professional Safety, 36-42.

ILO. (2001). Final Report-Meeting of Experts on ILO Guidelines on Occupational Safety and Health Management Systems. Geneva: International Labour Organization, 19-27.

Karageorgiou, A., Jensen, P. L., Walters, D., \& Wilt Hagen, T. (2000). Risk assessment in four Member States of the European Union. In Frick, K., Jensen, P. L., Quinlan, M., \& Wilt Hagen, T. (Eds.), Systematic occupational safety and health management: perspectives on an international development. Bingley: Emerald Group Publishing Limited.

Kartam, N. A. (1997). Integrating safety and health performance into construction. Journal of Construction $\begin{array}{llrl}\text { Engineering } \quad \text { Management, } & 123(2), & 121-126 .\end{array}$ http://dx.doi.org/10.1061/(ASCE)0733-9364(1997)123:2(121)

Leveson, N. (2004). A New Accident Model for Engineering Safer Systems. Safety Science, 42(4), 237-270. http://dx.doi.org/10.1016/S0925-7535(03)00047-X

NLNG. (2012). Facts and Figures on NLNG. Lagos: NLNG Public and Government Affairs Department.

Saksvik, P. Ø., \& Quinlan, M. (2003). Regulating Systematic Occupational Health and Safety Management: Comparing the Norwegian and Australian experience. Relations Industrielles/Industrial Relations, 58(1), 33-59. http://dx.doi.org/10.7202/007368ar

Sass, R., \& Butler, R. (1978). The Accident Proneness Theory: A Dead Horse that Won't Lie Down. Regina: Saskatchewan Department of Labour.

Smith, K. U. (1975). Behavioural Practices in Risk Management of Industrial Safety and Workers Compensation. D. I. L. H. R. Inter service Conferences on Systems Approaches to Risk Management of Workers Compensation. Industrial Safety and Health Systems Madison. WI: University of Wisconsin Behavioural Cybernetics Laboratory.

Smith, K. U. (1979). Human-Factors and Systems Principles for Occupational Safety and Health. Cincinnati. OH: National Institute of Occupational Safety and Health.

Viaene, J. (1980). Organization of Accident Prevention within the Enterprise. Proceedings of the Ninth World Congress on the Prevention of Occupational Accidents and Diseases. Amsterdam.

Walters, D., \& Jensen, P. L. (2000).The discourses and purposes behind the development of the EU Framework Directive 89/391/EEC. In Frick, K., Jensen, P. L., Quinlan, M., \& Wilt Hagen, T. (Eds.), Systematic occupational safety and health management: perspectives on an international development. Bingley: Emerald Group Publishing Limited. 
Walters, D., Wilt Hagen, T., \& Jensen, P. L. (2002). Introduction 'Regulating Health and Safety Management in the European Union. In Walters, D. (Ed.), Regulating Health and Safety Management in the European Union-A Study of the Dynamics of Change. Brussels: Presses Inter universitaires Européennes.

Whitelaw, J. (2001). Safety: What do you think? New Civ. Eng. Int., 11(2), 22-24.

Yamane, T. (1964). Statistics: An Introduction Analysis (3rd ed.). New York: Harper and Row Publishers.

\section{Copyrights}

Copyright for this article is retained by the author(s), with first publication rights granted to the journal.

This is an open-access article distributed under the terms and conditions of the Creative Commons Attribution license (http://creativecommons.org/licenses/by/3.0/). 